\title{
Second-Generation Phosgene and Diphosgene Detection Tube
}

\author{
Vladimír Pitschmann ${ }^{1,2}$, Lukáš Matějovský ${ }^{3, *} \mathbb{C}$, Jiří Zeman ${ }^{4}\left(\mathbb{D}\right.$, David Vetchý ${ }^{4}$, \\ Michal Dymák ${ }^{5}$, Martin Lobotka ${ }^{1}$, Sylvie Pavloková ${ }^{4}{ }^{\mathbb{B}}$ and Zdeněk Moravec ${ }^{6}\left[{ }^{6}\right.$ \\ 1 Oritest spol. s.r.o., Čerčanská 640/30, 14000 Prague, Czech Republic; pitschmann@oritest.cz (V.P.); \\ lobotka@oritest.cz (M.L.) \\ 2 Faculty of Biomedical Engineering, Czech Technical University in Prague, Sítná 3105, \\ 27201 Kladno, Czech Republic \\ 3 Faculty of Environmental Technology, University of Chemistry and Technology, Technická 5, \\ 16628 Prague, Czech Republic \\ 4 Department of Pharmaceutical Technology, Faculty of Pharmacy, Masaryk University, Palackého tř. 1946/1, \\ 61200 Brno, Czech Republic; zemanj@pharm.muni.cz (J.Z.); vetchyd@pharm.muni.cz (D.V.); \\ pavlokovas@pharm.muni.cz (S.P.) \\ 5 National Institute for Nuclear, Chemical and Biological Protection, Kamenná 71, \\ 26231 Milín, Czech Republic; dymak@sujchbo.cz \\ 6 Department of Chemistry, Faculty of Science, Masaryk University, Kotlářská 2, 61137 Brno, Czech Republic; \\ hugo@chemi.muni.cz \\ * Correspondence: lukas.matejovsky@vscht.cz
}

Received: 1 October 2020; Accepted: 29 October 2020; Published: 29 October 2020

\begin{abstract}
We have developed a second-generation detection tube for colorimetric and fluorescence detection of phosgene and diphosgene in air. The tube is packed with pellets made of a mixture of microcrystalline cellulose and magnesium aluminum metasilicate treated with a suitable monoterpene (camphor, menthol) to increase porosity and specific surface area. We impregnated the pellets with a specific $o$-phenylenediamine-pyronin (PY-OPD) based reagent. The detector with this novel indication charge enables phosgene or diphosgene to be selectively and sensitively detected at concentrations lower than as would those posing acute health risk. Owing to the analytical colorimetric and, at the same time, fluorescence signal, the detector is very robust while featuring good sensitivity and variability. The colorimetric limits of detection were $0.3 \mathrm{mg} / \mathrm{m}^{3}$ (tristimulus colorimeter), resp. $5 \mathrm{mg} / \mathrm{m}^{3}$ (with the naked eye), fluorescence detection limits of $0.3 \mathrm{mg} / \mathrm{m}^{3}$ (with the naked eye), all at an air sample volume of $1 \mathrm{dm}^{3}$. The response was practically immediate, acid vapors and gases, or diethyl chlorophosphate as a simulant of nerve warfare chemical agents, were disruptive.
\end{abstract}

Keywords: detection tubes; chemosensor; visual and fluorescence detection; phosgene; composite pellets

\section{Introduction}

Phosgene (carbonyl dichloride) and diphosgene (trichloromethyl chloroformate) are toxic compounds that damage the alveolar air/capillary air-blood barrier in the lungs. The change in the permeability of this barrier due to the action of the compounds gives rise to typical pulmonary edema, and the reduced resistance against secondary infection supports the development of bronchopneumonia. Inhalation toxicity of phosgene and diphosgene $\left(\mathrm{LCt}_{50}\right)$ is $3200 \mathrm{mg} \cdot \mathrm{min} / \mathrm{m}^{3}$, the maximum vapor concentration (volatility) is $4,300,000 \mathrm{mg} / \mathrm{m}^{3}$ for phosgene $\left(7.6{ }^{\circ} \mathrm{C}\right)$ and $45,000 \mathrm{mg} / \mathrm{m}^{3}\left(20{ }^{\circ} \mathrm{C}\right)$ for diphosgene [1]. Phosgene is an important industrial chemical in the organic synthesis domain. Both phosgene and diphosgene were one of the main types of chemical warfare agents used (CWA) 
in the deployment of major chemical weapons, mainly during World War I. Currently, phosgene is listed on Schedule 3 of the Chemical Weapons Convention. Hazards may arise from phosgene and, partly, diphosgene leaks during chemical industrial accidents and from civil wars and terrorist attacks in which the compounds are used as efficient chemical weapons.

Great attention is constantly paid to analytical methods for phosgene and diphosgene. Apart from technically advanced physical and physico-chemical detectors and analysers, attention is paid to rapid, simple, and inexpensive detection methods for phosgene/diphosgene in air based on color reactions using detection papers, strips, chalks, and detection tubes [2]. The traditional procedures and methods are based on a nucleophilic substitution reaction (acylation) of phosgene/diphosgene with analytical reagents such as $p$-dimethylaminobenzaldehyde [3-5], 4,4'-bis(dimethylamino)benzophenone [6,7], 4-(p-nitrobenzyl)pyridine [8,9], or anabasine [10]. A number of novel reagents providing colored reaction products that exhibit visible, often predominating fluorescence were developed during the past decade. Examples include chemosensors based on pyronine, rhodamine, iminocoumarin, BODIPY, and other organic compounds [11-25]. Their research is only at the laboratory stage, commercial evaluation is pending.

Detection tubes are among the most widespread simple tools to detect phosgene/diphosgene. They have different designs (the indication charge can be completed with a detection solution in an ampoule) and different sensitivity and selectivity levels, and they also have different resistance to the weather conditions and to ageing. Existing detection tubes are almost solely based on the reaction with 4-( $p$-nitrobenzyl)pyridine and $N$-phenylbenzylamine or with $p$-dimethylaminobenzaldehyde in combination with aniline derivatives [10]. Given the existence of new colorimetric and fluorescence reagents (chemosensors), it is not surprising that efforts are made to examine the feasibility of using them in detection tubes. Such devices can be referred to as 'second generation detection tubes'. The present work is devoted to the development of a detection tube with a chemosensor based on $o$-phenylenediamine-pyronine [12] in combination with a specifically prepared composite carrier. Such a device could be used for the orientational detection of phosgene/diphosgene in the armed forces and rescue services. We previously used this chemosensor for the preparation of a detection paper for use on liquid CWA [26].

\section{Materials and Methods}

\subsection{Chemicals}

Materials used for the preparation of carriers included menthol (Dr. Kulich Pharma, Hradec Králové, Czech Republic), camphor (Dr. Kulich Pharma, Hradec Králové, Czech Republic), magnesium aluminum metasilicate (Neusilin ${ }^{\circledR}$ US2, Fuji Chemical Industry, Toyoma, Japan), microcrystalline cellulose (Avicel ${ }^{\circledR}$ PH-101, FMC Biopolymer, Wallingstown, Ireland), microcrystalline cellulose and sodium carboxymethylcellulose (Avicel ${ }^{\circledR}$ RC-581, FMC Biopolymer, Brussels, Belgium), $o$-phenylenediamine-pyronin (PY-OPD, synthesized by the University of Chemistry and Technology, Prague, Czech Republic; the spectral data corresponded to the literature), chloroform (Merck, Darmstadt, Germany), and purified water (Ph. Eur. 10).

The tests were made with calibrated 1\% phosgene (Linde Gas, Prague, Czech Republic), diluted as required with air in $1 \mathrm{dm}^{3}$ Tedlar bags (SKC, Eighty Four, PA, USA). Diphosgene (Merck, Darmstadt, Germany) was used for the gas chamber test.

\subsection{Apparatus}

Instrumentation used for the preparation of carriers included a Stephan UMC 5 electronic mixer (A. Stephan \& Söhne, Hameln, Germany), a PharmTex 35T single-screw extruder and spheronizer (Wyss \& Probst Engineering, Ettlingen, Germany) and an AS200 Basic sieve shaker (Retsch, Haan, Germany). A MIRA3 scanning electron microscope (SEM) (Tescan Orsay Holding, Brno, Czech Republic) was used to obtain SEM images of the pellets. The samples were coated with a $20 \mathrm{~nm}$ gold layer by 
metal sputtering in argon atmosphere on a Q150R ES Rotatory-Pumped Sputter Coater/Carbon Coater (Quorum Technologies, Laughton, UK). A secondary electron detector was used, and accelerating voltage of $3 \mathrm{kV}$ was applied for the SEM measurement itself. The specific surface area of the samples was measured with the BET method on a Quantachrome Autosorb iQ3 gas porismeter (Quantachrome Instruments, Boynton Beach, FL, USA). The samples were degassed at $80^{\circ} \mathrm{C}$, which was reduced to $30{ }^{\circ} \mathrm{C}$ after attaining the pressure increase rate of $20 \mathrm{mtorr} / \mathrm{min}$, and the samples were kept under vacuum until the measurement.

The performance of the detection tubes was tested in a $0.5 \mathrm{~m}^{3}$ gas chamber equipped with a thermostat and a fan. The samples were taken with a manual aspiration system, stroke volume $100 \pm 5 \mathrm{~cm}^{3}$ (Kavalier, Votice, Czech Republic).

An LMG 173 tristimulus colorimeter (Dr. Lange, Düsseldorf, Germany) was used for the objective measurement of the indication charge color intensity. A $366 \mathrm{~nm}$ radiation wavelength was obtained from an L92 UV lamp (Leuchtturm, Geesthacht, Germany).

\subsection{Carrier Preparation}

A powder mixture of $44 \mathrm{~g}$ of Avicel ${ }^{\circledR}$ PH-101 microcrystalline cellulose, $11 \mathrm{~g}$ of Avicel ${ }^{\circledR} \mathrm{RC}-581$ microcrystalline cellulose with sodium carboxymethylcellulose, $25 \mathrm{~g}$ of magnesium alumino metasilicate (Neusilin ${ }^{\circledR}$ US2) and $20 \mathrm{~g}$ of menthol (batch M20.0) or camphor (batch C20.0) was homogenized in a mixer at $1500 \mathrm{rpm}$ for $5 \mathrm{~min}$ and subsequently wetted with purified water (mixture/water ratio 1:1.15) at a flow rate of $100 \mathrm{~mL} / \mathrm{min}$. The pellets were prepared from the moistened mass by extrusion/spheronization on an axial single-screw extruder/spheronizer at $60 \mathrm{rpm}$ through a grid of $1.25 \mathrm{~mm}$ mesh. The extrudate was then spheronized at $1000 \mathrm{rpm}$ for $20 \mathrm{~min}$. The product was dried in a hot air oven at $60{ }^{\circ} \mathrm{C}$ for $24 \mathrm{~h}$. The reference pellet batch $(\mathrm{N})$ contained neither menthol nor camphor. The physical properties of the pellets (bulk density, tapped density, Hausner ratio, hardness, friability, pycnometric density, interparticular and intraparticular porosity, and sphericity) were determined by conventional methods [27].

\subsection{Carrier (Pellet) Impregnation and Detection Tube Preparation}

A $100 \mathrm{~g}$ batch of $0.8-1.25 \mathrm{~mm}$ pellets was impregnated with $50 \mathrm{~mL}$ of $1 \%$ PY-OPD solution in chloroform. The impregnated pellets were allowed to air dry to complete solvent evaporation. Dry and non-agglomerated carriers, light-yellow in color, were stored in a hermetically sealed container protected from sunlight.

The detection tubes were prepared as follows: The charge was poured into a $5 \mathrm{~mm}$ diameter glass tube to obtain a $10 \mathrm{~mm}$ long layer. This was stabilized by using polyethylene (PE) elements to enable air to flow through the system. The tubes were hermetically sealed (the total length of $100 \mathrm{~mm}$ ). The construction of the detection tube and its use are shown in Figure 1.

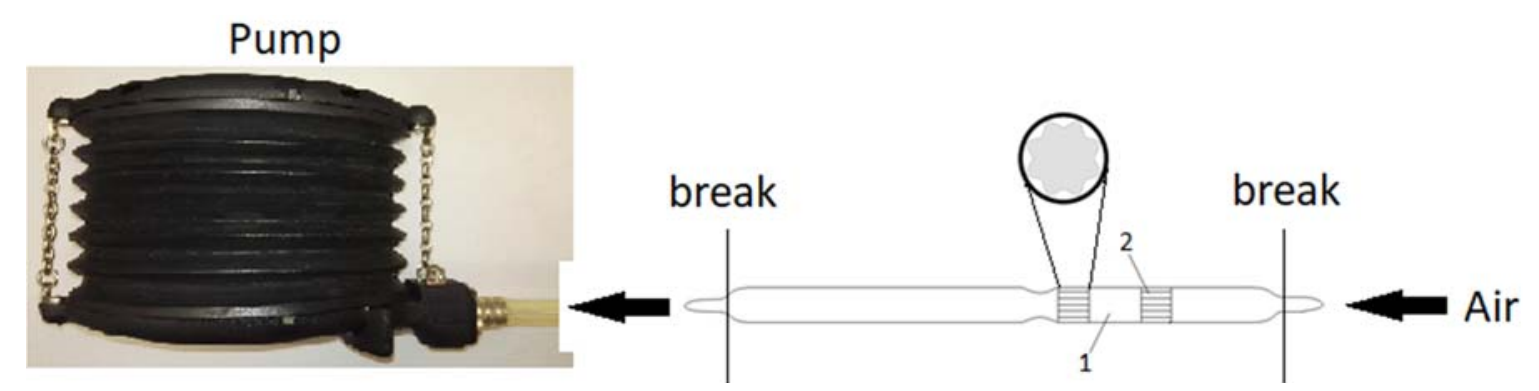

Figure 1. Detection tube design (1-indication charge; 2-PE element) and its use.

\subsection{Detection Tube Testing}

We selected testing in a gas chamber in which a specific volume of diphosgene solution in hexane had been evaporated, as the basic method of detection tube performance testing. The detection tube 
response to phosgene/diphosgene was evaluated based on (i) VIS color intensity assessed with the naked eye and measured on a tristimulus colorimeter; and (ii) intensity of fluorescence excited under a UV lamp (assessed with the naked eye). The stability of charge was tested on detection tubes exposed to elevated temperatures in a dryer for a prolonged period of time. The maximum temperature applied was $60{ }^{\circ} \mathrm{C}$ (selected with regard to the material of structural elements-polyethylene), the maximum heat burden duration was 2 months. The ageing process of the charge (evaluated with the naked eye and on the tristimulus colorimeter) and its response to phosgene/diphosgene in air were evaluated periodically. The color changes were evaluated based on the experience gained by the printing industry, where the human eye is capable of noting $\Delta \mathrm{E}$ values measured with a tristimulus colorimeter as follows: $\Delta \mathrm{E}<0.2$ imperceptible; $\Delta \mathrm{E}=0.2-0.5$ very weakly; $\Delta \mathrm{E}=0.5-1.5$ weakly; $\Delta \mathrm{E}=1.5-3.0$ clearly, $\Delta \mathrm{E}=3.0-6.0$ very clearly, $\Delta \mathrm{E}=6.0-12.0$ strongly, $\Delta \mathrm{E}>12.0$ very strongly.

\section{Results and Discussion}

\subsection{Properties of the Carrier}

Silica gel as a traditional carrier (treated with sodium carbonate) enabled a very sensitive charge with PY-OPD to be prepared, however, it was not adequately stable and failed to exhibit fluorescence, especially at low concentrations. This stimulated us to develop a specific carrier eliminating the above shortcomings of silica gel. Our laboratories have been studying the preparation and use of pellets with different compositions for a number of years. For example, we have developed composite pellets containing microcrystalline cellulose and $\mathrm{MgO}$ and proposed their use as carriers for 4-( $p$-nitrobenzyl)pyridine and $N$-phenylbenzylamine in phosgene/diphosgene detection tubes [9]. Other past experiments were aimed at increasing the pellet's sorption capacity by adding magnesium aluminum metasilicate; such carriers were then used in cholinesterase detection tubes serving to identify nerve chemical warfare agents [28,29]. As another method to attain still better sorption properties, the pellet mixture (microcrystalline cellulose and magnesium aluminum metasilicate) was treated with menthol or camphor. Comparative studies gave evidence that, unlike the previous types, such pellets are well suited to the preparation of indication charge for phosgene/diphosgene with the PY-OPD chemosensor, with a colorimetric and, at the same time, fluorescence indication effect. The best properties were observed with pellets treated with the highest fraction (20\%) of menthol or camphor (M20.0, C20.0). Such pellets had a much (approximately two-fold) larger specific surface area than the untreated pellets $(\mathrm{N})$, and this was not appreciably affected by impregnation with PY-OPD. We observed an increased interparticular porosity and for M20.0, also increased intraparticular porosity. Selected physical and structural properties of carriers are shown in Table 1 and Figure 2.

Table 1. Physical properties of pellets before and after impregnation with PY-OPD.

\begin{tabular}{ccccccc}
\hline Property & $\mathbf{N}$ & N/PY-OPD & M20.0 & M20.0/PY-OPD & C20.0 & C20.0/PY-OPD \\
\hline Bulk density, g/cm & N & $0.777 \pm 0.003$ & $0.758 \pm 0.006$ & $0.500 \pm 0.005$ & $0.502 \pm 0.001$ & $0.583 \pm 0.004$ \\
Tapped density, g/cm ${ }^{3}$ & $0.796 \pm 0.004$ & $0.790 \pm 0.007$ & $0.509 \pm 0.001$ & $0.520 \pm 0.002$ & $0.596 \pm 0.004$ & $0.624 \pm 0.000$ \\
Hausner ratio & $1.024 \pm 0.000$ & $1.042 \pm 0.005$ & $1.019 \pm 0.008$ & $1.036 \pm 0.005$ & $1.024 \pm 0.000$ & $1.060 \pm 0.004$ \\
Hardness, N & $11.99 \pm 1.57$ & $12.28 \pm 1.59$ & $3.64 \pm 0.48$ & $3.58 \pm 0.55$ & $6.99 \pm 1.12$ & $7.03 \pm 1.11$ \\
Friability, $\%$ & $0.14 \pm 0.03$ & $0.13 \pm 0.03$ & $0.19 \pm 0.04$ & $0.18 \pm 0.04$ & $0.17 \pm 0.04$ & $0.17 \pm 0.05$ \\
Pycnometric pellet density, g/cm ${ }^{3}$ & $1.6467 \pm 0.0065$ & $1.6459 \pm 0.0082$ & $1.6227 \pm 0.008$ & $1.6159 \pm 0.0019$ & $1.6596 \pm 0.0029$ & $1.6528 \pm 0.0015$ \\
Interparticular porosity, \% & $52.80 \pm 0.21$ & $53.97 \pm 0.35$ & $69.19 \pm 0.31$ & $68.95 \pm 0.09$ & $64.90 \pm 0.24$ & $64.41 \pm 0.00$ \\
Intraparticular porosity, \% & $2.76 \pm 0.38$ & $2.81 \pm 0.48$ & $4.02 \pm 0.05$ & $4.42 \pm 0.11$ & $2.29 \pm 0.17$ & $2.69 \pm 0.09$ \\
Sphericity & $0.982 \pm 0.010$ & $0.977 \pm 0.017$ & $0.986 \pm 0.010$ & $0.980 \pm 0.018$ & $0.982 \pm 0.012$ & $0.980 \pm 0.014$ \\
Specific surface area, $\mathrm{m}^{2} / \mathrm{g}$ & $65.90 \pm 0.84$ & $63.73 \pm 0.19$ & $121.14 \pm 5.32$ & $127.72 \pm 0.55$ & $113.44 \pm 3.44$ & $119.94 \pm 6.94$ \\
\hline
\end{tabular}

\subsection{Color Characteristics and Analytical Data}

The detection was based on the specific cyclization reaction of phosgene/diphosgene with the chemosensor PY-OPD (Figure 3) occurring on a specific composite carrier. This analytical reaction provided a violet product exhibiting clearly visible red fluorescence under a UV lamp. This fluorescence is characteristic of charges with this carrier at analytical concentrations (roughly up to $100 \mathrm{mg} / \mathrm{m}^{3}$ ). No fluorescence was observed if the treatment with menthol or camphor was omitted. The analytical 
signal was emitted almost immediately uniformly along the whole length of the indication charge and its intensity depended on the phosgene/diphosgene concentration in air.
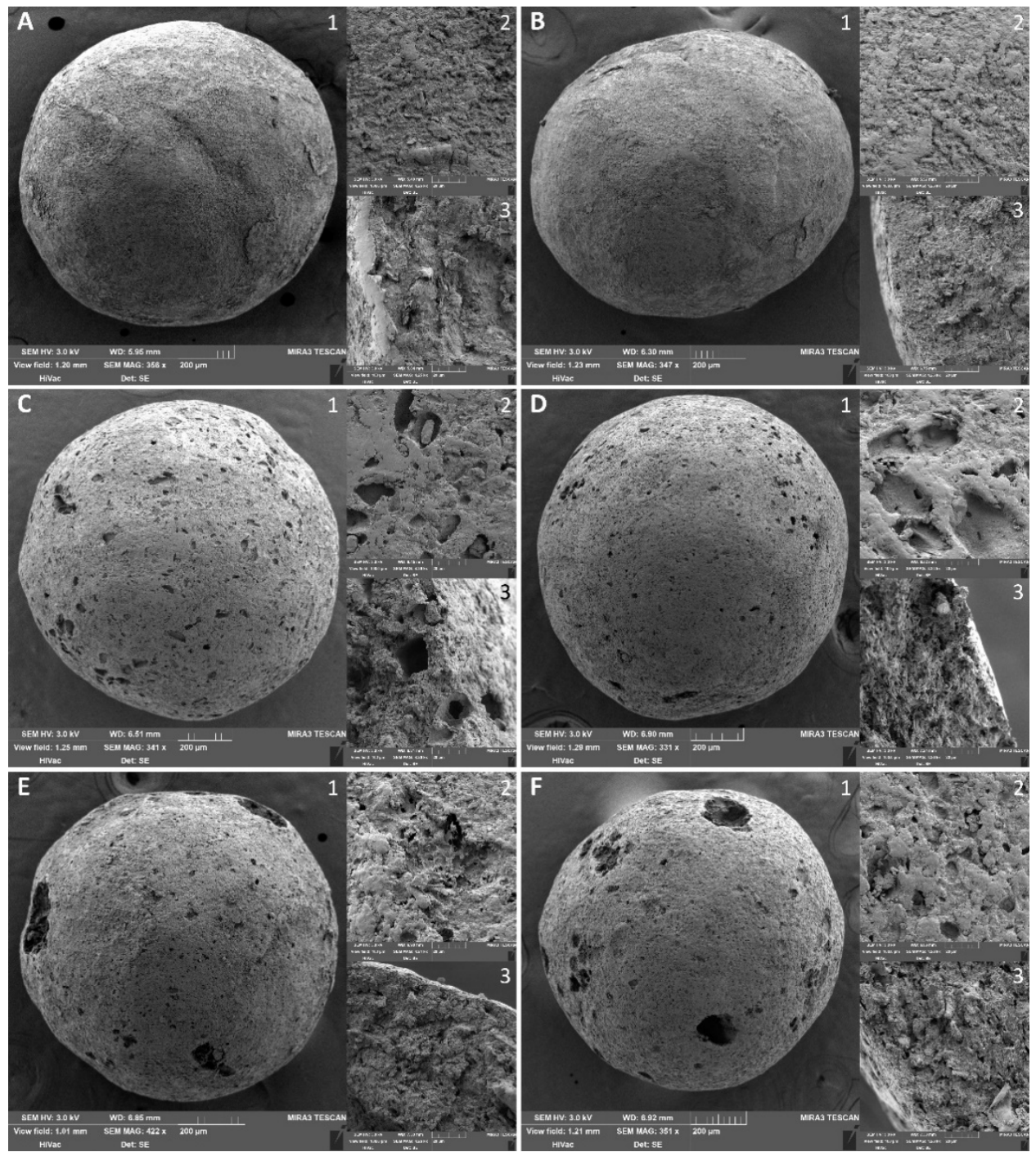

Figure 2. SEM images of pellets: (A)—reference pellet $(\mathrm{N})$ with no camphor or menthol; (B)—reference pellet, impregnated with PY-OPD; (C)—M20.0; (D)—M20.0 impregnated with PY-OPD; (E)—C20.0; (F) - C20.0 impregnated with PY-OPD; 1-whole pellet, 2-surface detail; 3-cross-section detail.

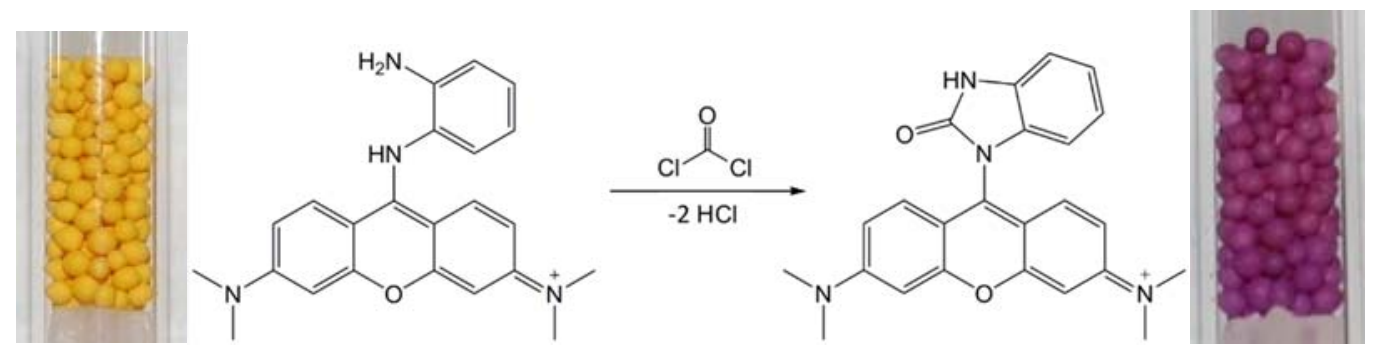

Figure 3. Phosgene reaction with PY-OPD and detection tube indication charge.

The sensitivity was verified and the phosgene/diphosgene detection limits (limit of detection, LOD) were assessed with the naked eye and measured instrumentally. This was made based on the color/visible fluorescence dependence on the analyte concentration within the range of $0-100 \mathrm{mg} / \mathrm{m}^{3}$, 
as shown in Figure 4. The color intensity increase $(\Delta \mathrm{E})$ measured on the tristimulus colorimeter is plotted in Figure 5.

From the obtained data, it can be deduced that the sensitivity of detection $(\mathrm{k}=\Delta \mathrm{E} / \mathrm{c})$ of the tristimulus by the colorimeter corresponded to the change of $\Delta \mathrm{E}=0.3$ with increasing unit concentration of the pollutant $\left(1 \mathrm{mg} / \mathrm{m}^{3}\right)$. In line with this, the LOD with the tristimulus colorimeter is $0.3 \mathrm{mg} / \mathrm{m}^{3}$ and the corresponding level for the naked eye is $5 \mathrm{mg} / \mathrm{m}^{3}$ for a sample $1 \mathrm{dm}^{3}$ volume. The LOD could be improved by increasing the sample volume-e.g., at air sampling of $3 \mathrm{dm}^{3}$; the colorimetric LOD was around $0.1 \mathrm{mg} / \mathrm{m}^{3}$ (tristimulus colorimeter), resp. $<2 \mathrm{mg} / \mathrm{m}^{3}$ (to the naked eye).

As demonstrated in Figure 4, the detection sensitivity under the UV lamp was higher than under natural daylight. It is estimated that the LOD for fluorescence observed with the naked eye was 10-fold lower, thereby reaching the LOD of the tristimulus colorimeter $\left(0.3 \mathrm{mg} / \mathrm{m}^{3}\right)$. We also examined the feasibility of objective fluorescence intensity measurement (Horiba Fluorolog 3 Extreme, Kyoto, Japan) the data, however, was not reproducible. The borosilicate glass tube material was especially disturbing. The use of a quartz glass or plastic tubing instead might be a solution to this problem. This will be the objective of our future research.

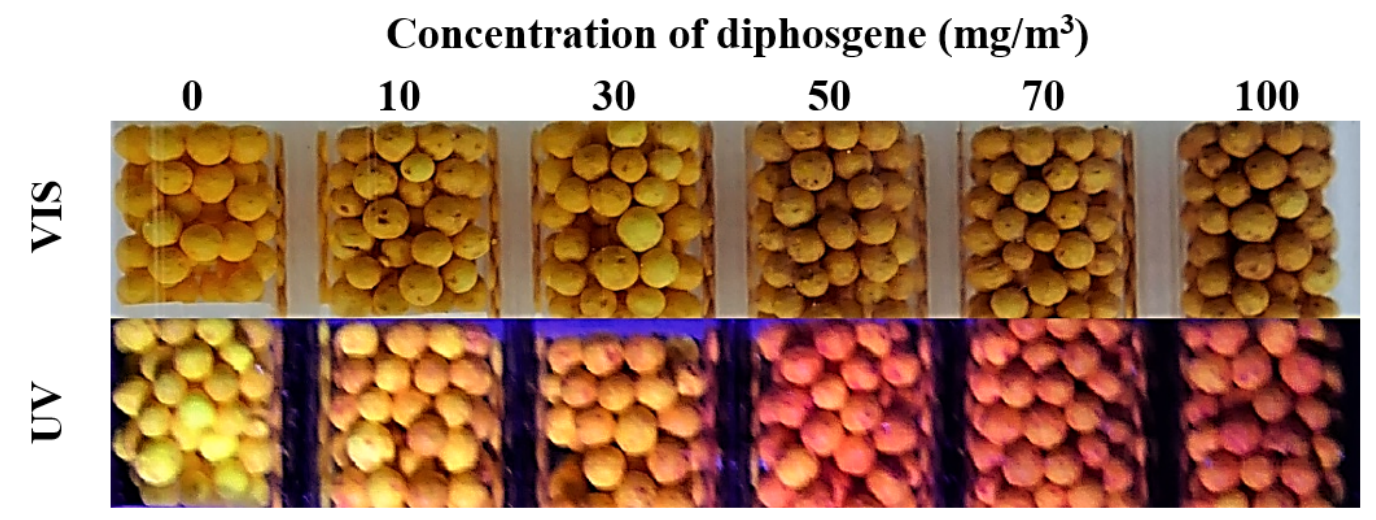

Figure 4. Dependence of the M20.0/PY-OPD charge VIS/UV color intensity on the concentration of diphosgene (the air volume was $1 \mathrm{dm}^{3}$ ).

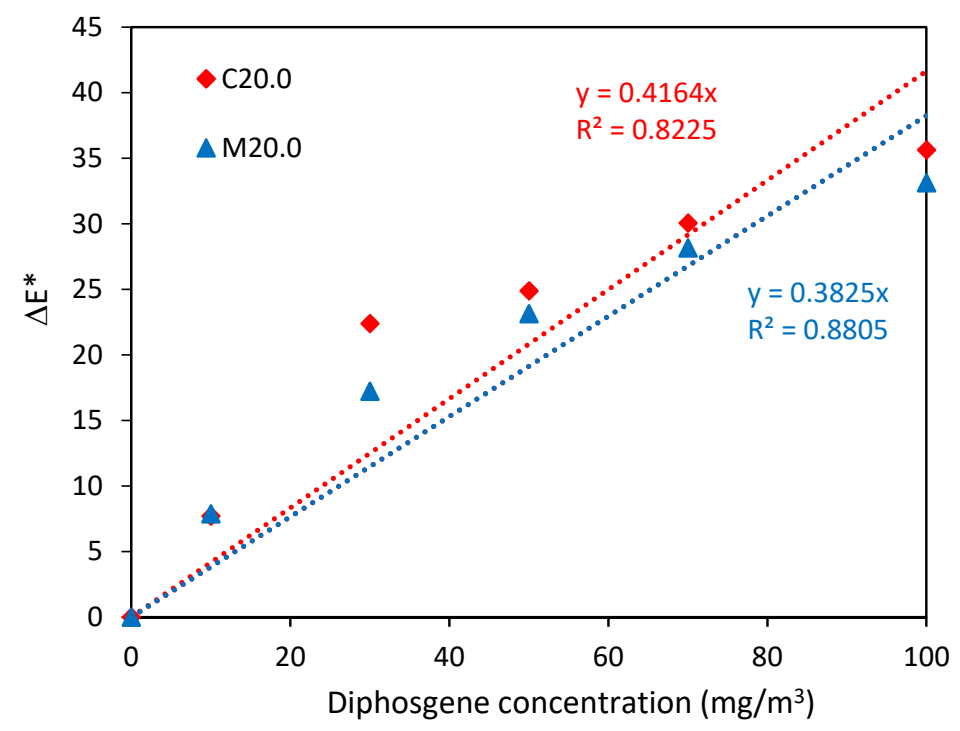

Figure 5. Charge color intensity (tristimulus colorimetry) in dependence on concentration of diphosgene (the air volume was $1 \mathrm{dm}^{3}$ ).

At this stage of the research, only the analytical data of the designed detection tube can be compared with the known 'first generation' detection tubes. Detection tubes for industrial use 
are designed to allow the detection of phosgene at the level of hygienic limits $\left(0.08-0.4 \mathrm{mg} / \mathrm{m}^{3}\right)$ or close concentrations. Therefore, they contain a sufficiently high indicator layer $(60-80 \mathrm{~mm})$, usually supplemented by a protective layer against interfering influences. They are evaluated according to the length of the color of the indicator layer. The second group consists of detection tubes used by the armed forces or rescue services to orient the phosgene/diphosgene, which are much simpler in construction, contain an indicator layer about $10 \mathrm{~mm}$ high and are usually part of special electric pumps/chemical semi-automatic detectors. Their detection limit (or the lower limit of the measuring range) is usually around $5 \mathrm{mg} / \mathrm{m}^{3}$ and they are evaluated mainly according to the intensity of the color of the indicator layer [2,30]. This group also includes the 'second generation' detection tube designed by us, which, in addition to colorimetric evaluation (in daylight), also enables evaluation based on fluorescence. The colorimetric detection limit (with the naked eye) meets the requirements of potential users, other detection limits (tristimulus colorimetry, fluorescence) significantly exceed them and approach the detection limits usual for calibrated detection tubes for industrial use. The proposed device is for single use only.

\subsection{Selectivity and Interferences}

The PY-OPD colorimetry/fluorescence chemosensor was initially developed by Zhou X. et al. [12] for the detection of phosgene and G-type nerve chemical warfare agents or their simulant diethylchlorophosphate (DCP) and for discerning one from the other. Hence, assessment of the effect of DCP on the proposed charge was a priority for us. In normal conditions, PY-ODP with DCP provides a yellow product by phosphorylation. However, the detection tube's composite charge on its own was light orange color, and so its interactions with low DCP concentrations could not be observed with the naked eye; a deeper orange color only resulted at high DCP concentrations (tube held above the open vial). When viewed under the UV lamp, the charge exposed to DCP vapors ( $\geq 250 \mathrm{mg} / \mathrm{m}^{3}$, sample volume $1 \mathrm{dm}^{3}$ ) provided yellow fluorescence (Figure 6).

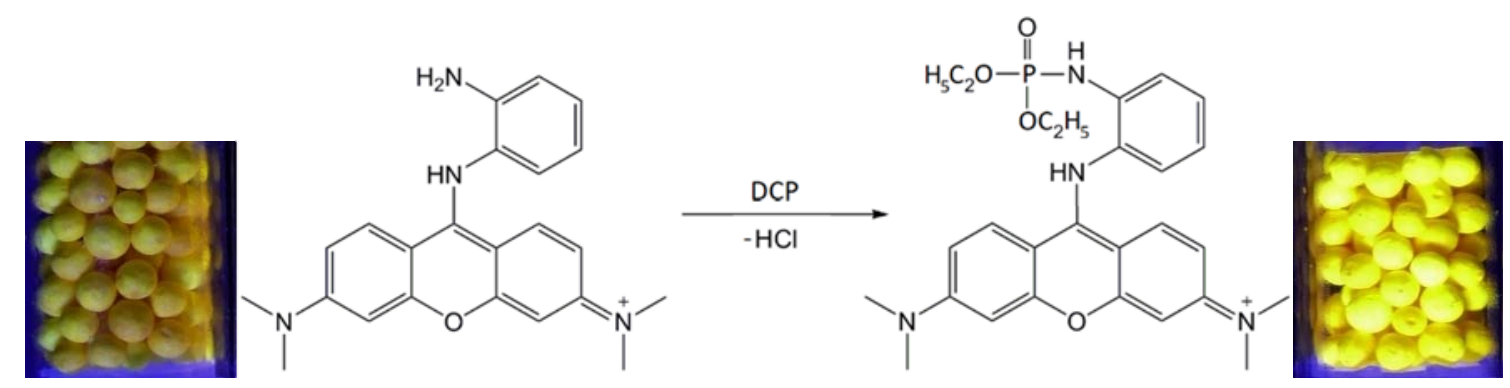

Figure 6. Schematic of the PY-OPD reaction with DPC and the effect of DCP fluorescence on the indication charge.

The PY-OPD reaction with phosgene/diphosgene gives rise to $\mathrm{HCl}$ (Figure 3), which can interfere with the detection. In fact, this problem has been tackled by Hu, Y. et al. [13], who developed a new chemosensor (rhodamine dye fused with benzimidazole), which does not generate $\mathrm{HCl}$. We took this issue into consideration when developing the composite charge for the detection tube but did not experience any interfering effect of spontaneous $\mathrm{HCl}$ formation on the phosgene/diphosgene detection. Therefore, we conclude that the composite material composition and properties create favorable reaction conditions. As demonstrated by Table 2, interfering effects only arose from the presence of very high concentrations of $\mathrm{HCl}$ (or acid compounds in general). Mixtures of diphosgene with toluene, acetone, hexane, and other common solvents did not interfere either. 
Table 2. Interference (C20.0, M20.0), sample volume $1 \mathrm{dm}^{3}$ (vapor above an open bottle).

\begin{tabular}{|c|c|c|}
\hline Chemical & Color Change/Daylight & Fluorescence \\
\hline Acetone & No & No \\
\hline Carbon disulphide & No & No \\
\hline Nitromethane & No & No \\
\hline Pyridine & No & No \\
\hline 2-(Butylamino)ethanethiol & Slight yellowing & No \\
\hline 2-Chloroethyl ethyl ether & No & No \\
\hline 2-Chloroethyl ethyl sulphide & No & No \\
\hline$N, N$-Dimethylformamide & Slight yellowing & No \\
\hline Ethylenediamine & Slight yellowing & No \\
\hline$N, N$-Dimethylethanolamine & Slight yellowing & No \\
\hline Hydrogen chloride & Deep orange color & Yellow \\
\hline Ammonia & Green-yellow color & No \\
\hline DCP & Deep orange color & Yellow \\
\hline Fuel petrol & No & No \\
\hline Nitric acid & Red-brown color & Yellow \\
\hline
\end{tabular}

\subsection{Stability (Temperature, Ageing)}

The degree of charge resistance to elevated temperatures was assessed from accelerated stability tests. Figure 7a illustrates the characteristic patterns of changes in the appearance $(\Delta \mathrm{E})$ of the $\mathrm{C} 20.0$ and M20.0 charges during heat stress at $60^{\circ} \mathrm{C}$ for 42 days. The two charges exhibited a similar increasing darkening trend, which did not differ significantly from the reference charge $(\mathrm{N})$. The tube charge darkening also correlated with the response to phosgene/diphosgene. Still, the two charges remained partly functional (color intensity was about $35 \%$ lower) in the 42 days of heat stress at $60^{\circ} \mathrm{C}$ (Figure $7 \mathrm{~b}$ ).

No appearance change or phosgene/diphosgene detection intensity decrease was observed after 4 months of charge storage in normal conditions (at $20^{\circ} \mathrm{C}$ ). Based on our experience we expect the detection tubes with the novel indication charge stored in typical storage conditions (at $\leq 30^{\circ} \mathrm{C}$ ) to be stable for 1 year as a minimum. In this respect, the detection tubes would match commercially available products.
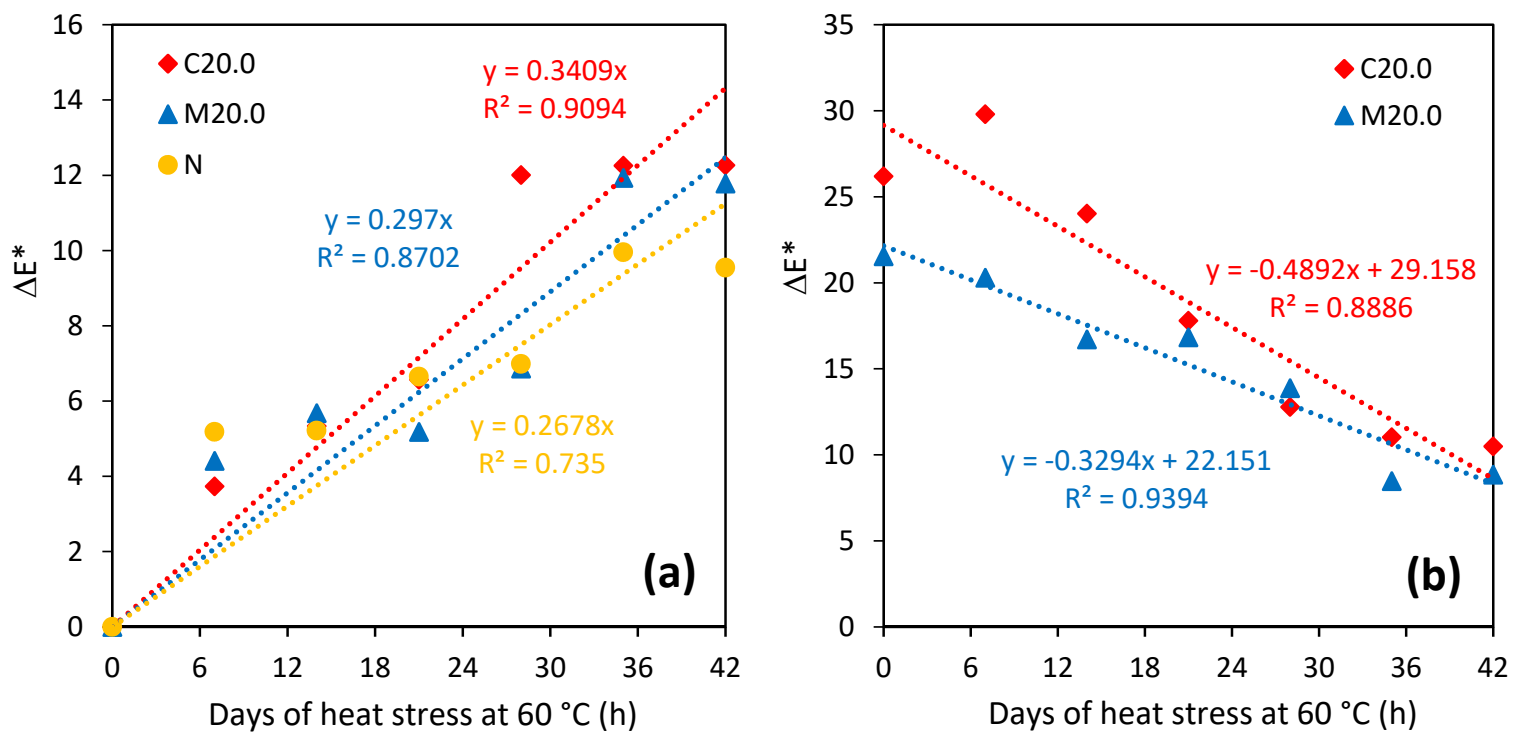

Figure 7. (a) Dependence of the indication charge appearance $(\Delta \mathrm{E})$ on the duration of heat stress at $60{ }^{\circ} \mathrm{C}$, and (b) dependence of the indication charge performance (response $\Delta \mathrm{E}$ to $20 \mathrm{mg} / \mathrm{m}^{3}$ of diphosgene) on the duration of heat stress at $60^{\circ} \mathrm{C}$. 


\section{Conclusions}

The newly designed simple detection tube for the orientation detection of phosgene/diphosgene in air enabling the response to be evaluated by colorimetric and fluorescence measurements seems (based on available sources) to be the first of this type. This result was achieved by combining the known (but only recently published) PY-OPD chemosensor with a new composite carrier, specifically developed for this purpose. This strategy appears to be promising. It enables scientists to test a range of chemosensors (recently published in scientific literature) and design additional non-conventional carriers (with emphasis on an increased sorption capacity and on compatibility with the chemosensor) for use in dangerous gas detection tubes. We believe that continuation of this research may bring about new interesting facts helping organic chemists in their efforts to synthesize an 'ideal' chemosensor for phosgene/diphosgene and, perhaps, also other dangerous chemical substances.

Author Contributions: Conceptualization: V.P., L.M., and J.Z.; Methodology: V.P., M.L., L.M., D.V., and J.Z.; Formal analysis: L.M., J.Z., S.P., Z.M., M.D., and L.M.; Validation: V.P., M.L., and L.M.; Writing-manuscript preparation: V.P. and L.M.; Writing-review and editing: V.P., L.M., D.V., and J.Z.; Resources: V.P.; Project supervisor: V.P. All authors have read and agreed to the published version of the manuscript.

Funding: The work was funded in the framework of a security research project of the Ministry of Interior of the Czech Republic, no. VI20192022172.

Conflicts of Interest: The authors declare that they have no competing interest.

\section{References}

1. Potential Military Chemical (Biological) Agents and Compounds; Field Manual FM 3-11.9; Exidyne: Weantzeville, MO, USA, 2005.

2. Halámek, E.; Kobliha, Z.; Pitschmann, V. Analysis of Chemical Warfare Agents; University of Defence: Brno, Czech Republic, 2009.

3. Moureu, H.; Chovin, P.; Truffert, L. The photochemical transformation of chloropicrin and phosgene characterization of the two corps. Compt. Rend. 1949, 228, 1954-1956.

4. Spěvák, A.; Kratochvíl, V. Rapid semiquantitative determination of concentration of phosgene in air. Chem. Prìm. 1965, 15, 682-685. (In Czech)

5. Vargas, A.P.; Gámez, F.; Roales, J.; Lopes-Costa, T.; Pedrosa, J.M. An optical dosimeter for the selective detection of gaseous phosgene with ultralow detection limit. ACS Sensors 2018, 3, 1627-1631. [CrossRef] [PubMed]

6. Linch, A.L.; Lord, S.S.; Kubitz, K.A.; De Brunner, M.R. Phosgene in air-Development of improved detection procedures. Am. Ind. Hyg. Assoc. J. 1965, 26, 465-474. [CrossRef] [PubMed]

7. Witten, B.; Prostak, A. Sensitive detector crayons for phosgene, hydrogen cyanide, cyanogen chloride, and lewisite. Anal. Chem. 1957, 29, 885-887. [CrossRef]

8. Dixon, B.E.; Hands, G.C. A field method for the determination of phosgene. Analyst 1959, 84, 463-464. [CrossRef]

9. Pitschmann, V.; Tusarová, I.; Kobliha, Z.; Vetchý, D. Detection tube with composite carrier for detection of phosgene and diphosgene in air. Chem. Ind. 2012, 66, 79-84. [CrossRef]

10. Forostyan, Y.N.; Efimova, E.I.; Oleinik, A.P. Products of the reaction of anabasine with phosgene. Chem. Nat. Compd. 1970, 6, 587-589. [CrossRef]

11. Hu, Y.; Chen, L.; Jung, H.; Zeng, Y.; Lee, S.; Swamy, K.M.K.; Zhou, X.; Kim, M.H.; Yoon, J. Effective strategy for colorimetric and fluorescence sensing of phosgene based on small organic dyes and nanofiber platforms. ACS Appl. Mater. Interfaces 2016, 8, 22246-22252. [CrossRef]

12. Zhou, X.; Zeng, Y.; Lilyan, C.; Wu, X.; Yoon, J. A fluorescent sensor for dual-chanel discrimination between phosgene and a nerve-gas mimic. Angew. Chem. Int. Ed. 2016, 55, 4729-4733. [CrossRef]

13. Hu, Y.; Zhou, X.; Jung, H.; Nam, S.-J.; Kim, M.H.; Yoon, J. Colorimetric and fluorescent detecting phosgene by a second-generation chemosensor. Anal. Chem. 2018, 90, 3382-3386. [CrossRef]

14. Wang, S.-L.; Zhong, L.; Song, Q.H. A ratiometric fluorescent chemosensor for selective and visual detection of phosgene in solutions and in the gas phase. Chem. Commun. 2017, 53, 1530-1533. [CrossRef] 
15. Liu, P.; Liu, N.; Liu, C.; Jia, Y.; Huang, L.; Zhou, G.; Li, C.; Wang, S. A colorimetric and ratiometric fluorescent probe with ultralow detection limit and high selectivity for phosgene sensing. Dye. Pigment. 2019, 163, 489-495. [CrossRef]

16. Feng, W.; Gong, S.; Zhou, E.; Yin, X.; Feng, G. Readily prepared iminocoumarin for rapid, colorimetric and ratiometric fluorescent detection of phosgene. Anal. Chim. Acta 2018, 1029, 97-103. [CrossRef]

17. Wu, X.; Wu, Z.; Yang, Y.; Asakura, T. A highly sensitive fluorogenic chemodosimeter for rapid visual detection of phosgene. Chem. Commun. 2012, 48, 1895-1897. [CrossRef]

18. Kim, T.I.; Hwang, B.; Bouffard, J.; Kim, Y. Instaneous colorimetric and fluorogenic detection of phosgene with a meso-oxime-BODIPY. Anal. Chem. 2017, 89, 12837-12842. [CrossRef] [PubMed]

19. Chen, L.; Wu, D.; Yoon, J. Recent advances in the development of chromofore-based chemosensors for nerve agents and phosgene. ACS Sens. 2018, 3, 27-43. [CrossRef] [PubMed]

20. Xia, H.C.; Xu, X.H.; Song, Q.H. A fluorescent chemosensor for selective detetion of phosgene in solutions and in gas phase. ACS Sens. 2017, 2, 178-182. [CrossRef] [PubMed]

21. Wang, S.L.; Li, C.; Song, Q.H. Fluorescent chemosensor for dual-chanel discrimination between phosgene and triphosgene. Anal. Chem. 2019, 91, 5690-5697. [CrossRef]

22. Wang, S.; Zhu, B.; Wang, B.; Fan, P.; Jiu, Y.; Zhang, M.; Jiang, L.; Hou, J.-T. A highly selective phenothiazine-based fluorescent chemosensor for phosgene. Dye. Pigment. 2020, 173, 107933. [CrossRef]

23. Zeng, L.; Zeng, H.; Wang, S.; Wang, S.; Hou, J.T.; Yoon, J. A paper-based chemosensor for highly specific, ultrasensitive, and instantaneous visual detection of toxic phosgene. Chem. Commun. 2019, 55, 13753-13756. [CrossRef] [PubMed]

24. Kundu, P.; Hwang, K.C. Rational design of fluorescent phosgene sensors. Anal. Chem. 2012, 84, 4594-4597. [CrossRef]

25. Chen, L.; Wu, D.; Kim, J.-M.; Yoon, J. An ESIPT-based fluorescence probe for colorimetric, ratiometric, and selective detection of phosgene in solutions and the gas phase. Anal. Chem. 2017, 89, 12569-12601. [CrossRef] [PubMed]

26. Pitschmann, V.; Matějovský, L.; Lunerová, K.; Dymák, M.; Urban, M.; Králík, L. Detection papers with chromogenic chemosensors for direct visual detection and distinction of liquid chemical warfare agents. Chemosensors 2019, 7, 30. [CrossRef]

27. Zeman, J.; Pavloková, S.; Vetchý, D.; Pitschmann, V. Double-coated pellets with semipermeable ethylcellulose coating for the detection of cholinesterase inhibitors. Ceska Slov. Farm. 2020, 69, 24-32. [PubMed]

28. Zeman, J.; Vetchý, D.; Pavloková, S.; Franc, A.; Pitschmann, V.; Dominik, M.; Urbanová, M.; Šeděnková, I. Tubes for detection of cholinesterase inhibitors-Unique effects of Neusilin on the stability of butyrylcholinesterase-impregnated carrier. Enzyme Microb. Technol. 2019, 128, 26-33. [CrossRef]

29. Zeman, J.; Vetchý, D.; Pavloková, S.; Franc, A.; Pitschmann, V. Unique coated neusilin pellets with a more distinct and fast visual detection of nerve agents and other cholinesterase inhibitors. J. Pharm. Biomed. Anal. 2020, 179, 113004. [CrossRef]

30. Oritest Detection Accessories, CHP-5. Available online: https://www.oritest.cz/en/products/detection/ accessories/chp-5-en/ (accessed on 29 October 2020).

Publisher's Note: MDPI stays neutral with regard to jurisdictional claims in published maps and institutional affiliations.

(C) 2020 by the authors. Licensee MDPI, Basel, Switzerland. This article is an open access article distributed under the terms and conditions of the Creative Commons Attribution (CC BY) license (http://creativecommons.org/licenses/by/4.0/). 